\title{
MEDICIÓN DE LA IMAGEN DE LA UNIVERSIDAD Y SUS EFECTOS SOBRE LA IDENTIFICACIÓN Y LEALTAD DEL EGRESADO: UNA APROXIMACIÓN DESDE EL MODELO DE BEERLI Y DÍAZ (2003)
}

\section{MEASUREMENT OF UNIVERSITY IMAGE AND ITS IMPACT ON GRADUATE IDENTIFICATION AND LOYALTY: AN APPROACH ON THE BASIS OF BEERLI AND DÍAZ'S MODEL (2003)}

\author{
Amparo Cervera ${ }^{1}$ y Walesska Schlesinger \\ UNIVERSIDAD DE VALENCIA \\ $M^{a}$ Ángeles Iniesta y Raquel Sánchez \\ UNIVERSIDAD DE ALMERIAA
}

\section{RESUMEN}

Dado el valor de la imagen para las instituciones, esta investigación desarrolla un modelo para la medición de la imagen de la Universidad percibida por sus egresados. Además, busca analizar la influencia que tiene esta imagen en la identificación y lealtad del egresado para con su institución. El análisis de resultados evidencia empíricamente la estructura cognitiva-afectiva de la imagen y su influencia positiva en la identificación y lealtad. Las conclusiones e implicaciones sugieren acciones encaminadas a la mejora de la gestión de la imagen de la universidad, haciendo énfasis en las dimensiones que tienen mayor peso en su formación.
Palabras clave: Imagen universidad, lealtad, identificación.

\section{ABSTRACT}

Given that image is the institution's most valuable asset, this research formulates and develops a model for measuring the university's image perceived by its graduates. Furthermore, an analysis of the influence of image on identification and loyalty is provided. Results confirm the cognitive-affective structure of the image and its positive influence on the graduates' levels of identification and loyalty. The conclusions and implications that arise from the results obtained suggest actions to improve

\footnotetext{
1 Autora de contacto: Amparo Cervera. Universidad de Valencia. Facultad de Economía. Avda. de los Naranjos s/n. 46022 Valencia. amparo.cervera@uv.es. La presente investigación ha sido elaborada en el marco del I+D+I del plan nacional SEJ2007-68105-C0201/ECON y SEJ2007-68105-C02-02/ECON del Ministerio Español de Educación y Ciencia.
} 
the management of the image of the University with an emphasis on the dimensions that obtained more weigh, among other aspects of interest.

Keywords: University image, identification, loyalty.

\section{INTRODUCCIÓN}

Las instituciones de educación necesitan desarrollar y/o mantener una imagen distintiva con el objetivo de crear una ventaja competitiva en un mercado crecientemente competitivo (Paramewaran y Glowacka, 1995). Los diferentes públicos de las universidades extraen conclusiones acerca de la imagen general de una institución a partir de las impresiones que tienen sobre sus fortalezas y debilidades (IvY, 2001).

En este sentido, el interés del trabajo proviene de varios aspectos. La movilidad estudiantil y del profesorado, la formación a lo largo de la vida, el avance de las nuevas tecnologías de la información (TIC) y la empleabilidad, son algunos de los factores señalados como claves en la conocida declaración de Bolonia de $1999^{2}$. Esto resulta en un llamamiento a la competitividad, no sólo de las universidades españolas y europeas, sino a nivel mundial. De esta forma, los "activos intangibles" de las organizaciones - como la imagen institucionaltienen un papel importante en el desarrollo de un acercamiento mayor al "cliente". Así, se podría decir que los activos intangibles marcarán la diferencia en el Espacio Europeo de Educación Superior (EEES) (CARRILlO y RUAO, 2005).

Por otra parte, la consideración de la imagen corporativa como un concepto multidimensional se hace extensible al contexto universitario, constituyendo un ámbito de interés como obje- to de estudio y como fuente de aplicaciones prácticas de la gestión del marketing (LANDRUM et al., 1998; BEERLI y DÍAZ, 2003; ARPAN et al., 2003; ALESSANDRI et al., 2006; LUQUE y DEL BARRIO, 2008).

Sin embargo, a pesar de su importancia, se requiere un mayor esfuerzo investigador en torno al fenómeno de la imagen. En particular, uno de los aspectos que deben explorarse con mayor empeño es la estructura que define o caracteriza la imagen de la universidad. De este modo, mediante el análisis de su naturaleza podrán conocerse las verdaderas dimensiones que definen el concepto y que son percibidas por los grupos de interés o stakeholders de la universidad.

La imagen de la Universidad constituye un tema de investigación emergente que suscita un renovado interés, ya que la investigación académica en torno a este tema ha estado tradicionalmente enfocada hacia el estudio del emisor y del proceso de construcción de mensajes, descuidando las aproximaciones cuyo objeto de estudio estuviese centrado en el receptor (CORNELLSSEN, 2000; CAPRIOTTI, 2006). Este hecho confiere a los estudios empíricos de la imagen de la Universidad orientados al receptor una valoración especialmente novedosa y atractiva (PARAMESWARAN y GlowACKA, 1995; LANDRUM ET AL., 1998; KAZOLEAS ET AL., 2001; BEERLI y DíAz, 2003; ArPAn et al., 2003; CuBILlo et al., 2006; TRAVERSO et al., 2007).

En este sentido, el objetivo de esta investigación es, a partir de las bases teóricas y resultados empíricos de estudios de imagen de la universidad ya realizados (LANDRUM et al., 1998; KAZOLEAs et al., 2001; BeERli y DíAz, 2003; ARPAN et al., 2003), y en especial de la propuesta de BEERLi y DíAz (2003) en el ámbito español, retomar la multidimensionalidad del concepto para su confirmación, pero dando unos pasos más allá, al proponer la configuración de este constructo como uno de orden

\footnotetext{
${ }^{2}$ En esta Declaración de Bolonia (1999) y la Declaración de la Sorbona (1998) se da inicio al denominado proceso de Bolonia, que es en la actualidad objeto de debate social.
}

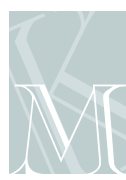


superior y con componentes actitudinales: cognitivos y afectivos. Además, trata de analizar el efecto de este constructo en variables como la identificación y la lealtad del egresado hacia la institución.

Para alcanzar los objetivos propuestos, se diseñó y ejecutó una investigación empírica de carácter cualitativo y cuantitativo, en el que se contrastan las hipótesis propuestas, basado en la réplica y extensión del trabajo de BEERLI et al. (2002) y BEERLi y DíAz (2003), empleando técnicas de análisis de estructuras de covarianzas de los datos provenientes de una muestra probabilística de 500 egresados de una universidad española, la Universidad de Valencia (UV). El desarrollo, resultados, y principales conclusiones y aportaciones derivadas de dicha investigación a la literatura en marketing y de la educación superior se presentan a continuación.

\section{PLANTEAMIENTOS TEÓRICOS E HIPÓTESIS}

\subsection{Delimitación conceptual de la imagen institucional}

La imagen es un constructo complejo que ha sido definido en la literatura como una red de significados almacenados en la memoria (REYNOLDS y GUTMAN, 1984), un proceso originado por ideas, sensaciones y experiencias previos con el objeto que están reconocidos y transformados en un cuadro mental (MCINNIS y PRICE, 1987), o una representación de la suma de creencias, actitudes e impresiones que una persona o grupo tiene de un objeto (BARICH y KotLER, 1991), entendiendo como tal una marca, un producto o servicio, un evento, un lugar, una organización, una persona, o incluso uno mismo (autoimagen).

Como punto de partida para una tipología, es necesario remarcar que la imagen es un "producto" del receptor, es una idea, concepto o actitud, que se forma como consecuencia de la interpretación de todas las informaciones que le llegan sobre algo o alguien. En un principio se creyó que la imagen corporativa era un "producto" de la organización, el cual debía ser transmitido a los públicos (CAPRIOTTI, 2006). Sin embargo, las investigaciones en el campo de la percepción y de la comunicación llevaron a la modificación de esta concepción. Los públicos no son sujetos pasivos, sino "sujetos creadores": la imagen de la institución se genera en los públicos, es el resultado de la interpretación que hacen éstos de la información o desinformación sobre la organización (KAZOLEAS et al., 2001).

A partir de las distintas definiciones de imagen corporativa o institucional cabe destacar, en primer lugar, que una imagen consiste en una combinación de varios componentes (NGUYEN y LeBlanc, 2002; Cervera et al., 2008) de naturaleza intangible y subjetiva (NGUYEN y LEBLANC, 1998), pudiendo haber tantas imágenes del mismo objeto como públicos diferentes (COSTA, 2001; CAPRIOTTI, 2006).

Se ha creído conveniente agrupar los tres enfoques presentados por CAPRIOTTI (2006), los cuales permitirán observar las grandes tendencias existentes sobre la imagen en ese campo de estudio, y así justificar la concepción en torno a la imagen en esta investigación. De esta manera, se pueden estructurar esas interpretaciones en tres grandes concepciones: a) la imagen-ficción; b) la imagen-icono; c) la imagenactitud (resumidas en la tabla 1 ). 
TABLA 1

Concepciones de la Imagen Corporativa

\begin{tabular}{|c|c|c|}
\hline $\begin{array}{c}\text { CONCEPCIONES } \\
\text { DE LA } \\
\text { IMAGEN }\end{array}$ & CARACTERÍSTICAS & CRÍTICAS-APLICACIONES \\
\hline Imagen-ficción & $\begin{array}{l}\text { Se concibe como "un perfil de personalidad, } \\
\text { estudiosamente fabricado, de un individuo, } \\
\text { institución, corporación, producto o servicio" } \\
\text { Boorstin (1977: 186). Esta concepción es la de } \\
\text { imagen como apariencia de un objeto o de un } \\
\text { hecho, como acontecimiento ficticio que no es } \\
\text { más que un reflejo manipulado de la realidad. } \\
\text { Las cosas no son lo que son, sino lo que las } \\
\text { personas creen, perciben o conocen de ellos. }\end{array}$ & $\begin{array}{l}\text { Las críticas a esta concepción se centran } \\
\text { en que los autores parten de la idea de } \\
\text { que la imagen es una falsificación de la } \\
\text { realidad. Sin embargo, no hay nada irre- } \\
\text { al sobre la imagen de la organización, } \\
\text { porque para la persona, la imagen es la } \\
\text { organización. Si la imagen es verdadera } \\
\text { o falsa, es aparte; la persona que la tie- } \\
\text { ne piensa que es verdadera y actúan } \\
\text { según ello, pues es su realidad. }\end{array}$ \\
\hline Imagen-icono & $\begin{array}{l}\text { Es una representación visual que materializa } \\
\text { un fragmento del mundo perceptivo (Moles, } \\
\text { 1983). } \\
\text { Imagen material, "lo que se ve" de una organi- } \\
\text { zación (logotipo, colores corporativos, arqui- } \\
\text { tectura, uniformes). Como resultado, esque- } \\
\text { mas de realidad, representaciones simplifica- } \\
\text { das y abstractas de un objeto, que vienen a } \\
\text { constituir el icono mental. }\end{array}$ & $\begin{array}{l}\text { Se le critica su postura restrictiva a los } \\
\text { aspectos superficiales de la organiza- } \\
\text { ción, puesto que en la imagen entran } \\
\text { otros elementos tales como, el contexto } \\
\text { general y específico, las experiencias } \\
\text { previas con la organización y la infor- } \\
\text { mación que se tiene de ella entre otros. }\end{array}$ \\
\hline Imagen-actitud & $\begin{array}{l}\text { La imagen es aquella representación mental, } \\
\text { cognitiva, afectiva y valorativa, que los indivi- } \\
\text { duos se forman del ente en sí mismo (Cheli, } \\
\text { 1992). } \\
\text {-Componente cognitivo: cómo se percibe la } \\
\text { organización. } \\
\text {-Componente afectivo: sentimientos que pro- } \\
\text { voca la organización al ser percibida. } \\
\text {-Componente conativo: predisposición a } \\
\text { actuar de una manera determinada ante una } \\
\text { organización. }\end{array}$ & $\begin{array}{l}\text { Cappriotti (2006) añade al concepto de } \\
\text { icono visual el de icono mental, que es } \\
\text { la concepción de la imagen como repre- } \\
\text { sentación mental, concepto o idea acer- } \\
\text { ca de un objeto o persona. Es la noción } \\
\text { psicológica del término. } \\
\text { Una de las críticas es que se piensa que } \\
\text { la imagen de la organización es propie- } \\
\text { dad de ella y no del receptor, como en } \\
\text { realidad es. }\end{array}$ \\
\hline
\end{tabular}

Fuente: Elaboración propia a partir de CAPRIOTTI (2006).

La imagen-ficción se concibe como "un perfil de personalidad, estudiosamente fabricado, de un individuo, institución, corporación, producto o servicio" Boorstin (1977: 186). Las cosas no son lo que son, sino lo que las personas creen, perciben o conocen de ellas. Las críticas a esta concepción se centran en que los autores parten de la idea de que la imagen es una falsificación de la realidad. La imagen-icono es la imagen material, "lo que se ve" de una organización (logotipo, colores corporativos, arquitectura, uniformes). Como resultado, se generan esquemas de realidad, representaciones simplificadas y abstractas de un objeto, que 
vienen a constituir el icono mental. Se le critica su postura restrictiva a los aspectos superficiales de la organización (CAPRIOTTI, 2006). Finalmente, la imagen-actitud es aquella representación mental, cognitiva, afectiva y valorativa, que los individuos se forman del ente en sí mismo (CHELI, 1992).

A manera de conclusión, se considera que tanto la noción de imagen-icono como la noción de imagen-ficción, puede considerarse correctas desde la perspectiva etimológica de los términos, pero no son adecuadas para definir lo que es la imagen de una organización. La imagen-actitud añade la representación mental, ese concepto, esa idea que se hace de un objeto. No es el objeto como tal, sino una "evaluación" que se hace de él por la cual se le otorgan ciertas características con las que se define y diferencia de los demás objetos (CAPRIOTTI, 2006). Esta evaluación implica una valoración, una toma de posición con respecto al objeto $\mathrm{y}$, en consecuencia, una forma de actuar en relación con él.

A fin de operacionalizar la noción de imagen, diversos autores tendieron a considerarla como una actitud o como un conjunto de actitudes basadas en atributos evaluados (ENGEL et al., 1990; CAPRIOTTI, 2006). De esta forma, de la mano de la investigación científica sobre actitudes, la consideración de los componentes cognitivo y afectivo de la imagen va adquiriendo un mayor protagonismo doctrinal, en la medida en que los trabajos empíricos cuyo objeto de estudio se centraba en actitudes superaban el modelo unidimensional propuesto por FishBeIN y AJZEN (1975). En este sentido, los resultados del estudio de BAGOzZI y BuRNKRANT (1985) y BEERLI y DÍAZ (2003) permiten concluir que el tratamiento separado de respuestas cognitivas y afectivas lleva a una mejor representación de la estructura actitudinal y de la predicción del comportamiento.

Dentro de esta investigación se tratará la imagen desde esta última concepción, es decir, imagen como una actitud, tomando las definiciones de CostA (2001) y CAPRIOTTI (2006) que consideran la imagen como una representación mental de un estereotipo de un objeto, organización, persona o acontecimiento, que los públicos se forman como consecuencia de la interpretación de la información acerca de aquéllos y capaz de influir en los comportamientos y modificarlos. Además, haciendo énfasis en que la imagen institucional debe ser estudiada y analizada desde la perspectiva de los públicos o grupos de interés de la organización y de su interpretación de la organización, más que desde el ángulo de la organización, y de la construcción de los mensajes que ella realiza. Sobre la base de esta postura, se considera necesario profundizar en los diferentes componentes o dimensiones de la imagen.

\subsubsection{Multidimensionalidad de la imagen}

Existe un consenso en la literatura académica sobre la multidimensionalidad de la imagen de una organización (GARCÍA DE LOS SALMONes, 2001; NGuyen y Le Blanc, 2002; BeERli y Díaz, 2003; Arpan et al, 2003). Sin embargo, no existe consenso acerca de los elementos constituyentes de dicha variable (NGUYEN y LeBlanc, 2002). En la revisión de la literatura, se observa que autores como IVy (2001) y Martensen et al. (1999) la conciben de manera unidimensional. Por otra parte, otros autores (Kazoleas et al., 2001; BeErli et al., 2002; BeErli y Díaz, 2003; Arpan et al., 2003; CuBILLO et al., 2006; LuQUe y DEL BARRIO, 2008) la conciben como un concepto multidimensional. En este sentido, se manifiesta el carácter subjetivo y complejo que tiene el concepto de imagen corporativa y la falta de consenso que existe en torno a su medición. Sin embargo, el estudio de las dimensiones que integran la imagen institucional se aborda en este trabajo mediante la postura que reivindica la existencia de dos componentes básicos de la imagen: cognitivo y afectivo.

Siempre que se desee captar, en toda su amplitud, la riqueza de la imagen de una uni- 
versidad (BEerli et al., 2002; BEerli y DíAZ, 2003) se debe incluir el componente cognitivo y el componente afectivo, puesto que se facilita la comprensión y medida de la imagen. En conclusión, según los planteamientos anteriores, la coexistencia de las dimensiones cognitiva y afectiva en el estudio de la imagen permite explicar mejor la representación que tiene para sus grupos de interés. Ambas dimensiones de la imagen se complementan, puesto que el componente cognitivo se fundamenta en el conocimiento sobre la organización, mientras que el afectivo se relaciona con las motivaciones, sentimientos y beneficios buscados, con lo cual se considera un enfoque válido para esta investigación, pretendiéndosevalidar a través del estudio empírico.

\subsubsection{Delimitación conceptual de la imagen de la universidad}

La imagen institucional de la universidad tiene una importante incidencia en (1) las decisiones de sus clientes, teniendo un efecto tanto en la retención de los estudiantes actuales como en la atracción de los potenciales (LANDRUM et al., 1998; Helgesen y NeSSET, 2007) y (2) las actitudes de otros públicos que pueden afectar a su nivel de financiación (LANDRUM et al., 1998). Esta importancia de la imagen en el contexto universitario constituye un nuevo ámbito de interés como objeto de estudio y en el campo de aplicaciones prácticas de la gestión del marketing (PARAMESWARAN y GLOWACKA, 1995; Kazoleas et al. 2001; BeErli et al., 2003; AlEsSANDRI et al., 2006; TrAVERso et al. 2007; LuQue y Del BARRIo, 2008).

En definitiva, el estudio de la imagen de la Universidad es complejo y requiere contemplar múltiples aspectos y dimensiones que deberán ser evaluados por los diferentes stakeholders relacionados con esta institución. De acuerdo a lo desarrollado en el epígrafe anterior, la imagen de la universidad en esta investigación es considerada como un constructo multidimen- sional, con componentes cognitivos y afectivos, desde el enfoque de imagen-actitud, y se medirá la imagen percibida por un stakeholder muy importante: los egresados, a partir de las dimensiones cognitivas y afectivas propuestas por BEERLi y DíAz (2003), las cuales se detallan a continuación:

1. Orientación y capacitación de la universidad: esta dimensión se refiere a la orientación que tiene la Universidad hacia sus diferentes grupos de interés: alumnos, sociedad, empresas, así como la calidad de su formación.

2. Reputación: esta dimensión tiene que ver con su prestigio y fama percibida por sus grupos de interés.

3. Masificación: relativa a la relación alumnos/profesor y el costo para aquellas personas interesadas en ingresar a ella.

4. Accesibilidad: se relaciona con la imagen que tienen sus públicos sobre su facilidad para ingresar a ella.

5. Edad: mide la imagen de juventud que pueda ser percibida.

6. Afectiva: se refiere a los aspectos más de carácter emocional relacionados con la imagen de la universidad.

En este sentido, con la finalidad de validar la coexistencia de dichas dimensiones en el estudio de la imagen, de tal manera que permitan explicar mejor la representación que tiene para sus grupos de interés sobre la base de los resultados obtenidos por KAZOLEAS et al. (2001), García de los Salmones (2001), BeERli y DíAZ (2003), AleXANDri et al. (2006), CERVERA et al. (2008) y LUQUE y DEL BARRIO (2008), $\mathrm{y}$ en atención al objetivo de la investigación anteriormente citado, se propone la siguiente hipótesis (Figura 1):

\section{$H_{1}$ : La imagen percibida de la universidad es un constructo multidimensional con com- ponentes cognitivos y afectivos.}




\subsection{Consecuencias de la imagen percibida de la universidad}

\subsubsection{Identificación Egresado-Universidad $(E-U)$}

El concepto de identificación se ha estudiado tradicionalmente en la literatura de organización de empresas, analizando las relaciones que existen entre la empresa y sus stakeholders y, más frecuentemente, entre sus trabajadores (CARMeli et al., 2006; Hup, 2006). DutTON et al. (1994: 242) señalan que "cuando el autoconcepto del individuo contiene los mismos atributos que percibe en la identidad organizativa, se produce una conexión cognitiva que definimos como identificación organizativa". En este sentido, se puede decir que la identificación organizativa es un tipo concreto de identificación social, en el que grupo o categoría social donde se sitúa el sujeto es una organización (MAEL y ASHFORTH, 1992).

Es importante aclarar que la identificación no es únicamente la conciencia de pertenencia de un individuo a la organización, sino que supone también un determinado criterio de solapamiento o coincidencia entre identidades (BERGAMI y BAGOZZI, 2000; BHATTACHARYA y ElsBach, 2002). Según Bergami y Bagozzi (2000), la identificación organizativa se basa en una autopercepción de conexión y cercanía del sujeto con la organización, de manera que no es la correspondencia directa y objetiva entre sus propias características personales y las de la organización, sino que se deriva de un sentido subjetivo de conformidad entre ambas identidades.

De la revisión de la literatura se desprende que este concepto ha sido poco investigado en el área no lucrativa, pues sólo algunos trabajos han sido aplicados en este contexto (BHATTACHARYA et al., 1995; ElSBACH y BHATTACHARYA, 2001) y, específicamente, el de MAEL y AsHFORTH (1992) en el ámbito educativo. Excluyendo estas referencias, no se han encontrado investigaciones empíricas que profundicen en la identificación que tiene lugar entre un alumno y su universidad, así como la confirmación de aquellas variables que influyen en ella.

Desde el enfoque propuesto por ScotT y LANe (2000) y BhatTacharya y Sen (2003), y para los fines de esta investigación, se define la identificación E-U como una relación voluntaria, activa y selectiva mantenida por el egresado con la universidad con el objetivo de satisfacer una o más de sus necesidades de definición personal, tomando como base la existencia de unos valores y principios compartidos.

Diversas investigaciones han podido confirmar que la forma en cómo es percibida la organización (la evaluación que se haga de ella, su imagen) va a influir en la identificación Consumidor-Empresa (C-E) (DUTTON et al., 1994; AHEARNe et al., 2005; MARín y RUIZ, 2007). Asimismo, diversas investigaciones han explorado la influencia sobre la identificación C-E de diferentes características de la identidad de la organización que favorecen la satisfacción de dichas necesidades de autodefinición; en esta línea, se ha demostrado que el prestigio o reputación de la organización mejora el atractivo de la identidad y la identificación C-E (BHATTACHARYA et al., 1995; KreINER y AsHFORTH, 2004; CORNWELl y COOTE, 2005), por cuanto que vinculándose con una organización de prestigio, el consumidor puede satisfacer eficazmente su necesidad de mejora o realce del yo (DutTon et al., 1994; Bhattacharya y SEN, 2003). Por ello, se puede plantear la siguiente hipótesis:

\section{$\mathrm{H}_{2}$ : La imagen percibida por los egresados de la Universidad influye directa y positiva- mente en su identificación con la institu- ción.}

\subsubsection{Lealtad}

Las diferentes conceptualizaciones y operacionalizaciones utilizadas en discusiones e investigaciones empíricas sobre la lealtad del 
consumidor, en menor o mayor grado, tienen algo en común: se refieren a la relación del consumidor con un objeto específico a lo largo del tiempo, ya sea el vendedor, marca, detallista o proveedor de servicio (SöDERLUND, 2006). En este sentido, la lealtad implica un cierto nivel de continuidad en la relación del consumidor con ese objeto y en la forma en la que se da esa relación. De esta manera, la ampliación más extendida de este concepto -más allá de la mera repetición de compra- es la que defiende la naturaleza intencionada y determinista de la lealtad y la concibe como un vínculo psicológico o emocional del consumidor hacia un producto, servicio, marca u organización, representando por tanto la promesa explícita o implícita de continuar con la elección de dicho objeto (DELGADO, 2004).

Dada las características actuales del entorno de las universidades, tales como la reducción del número de estudiantes que ingresan, el aumento de los que abandonan los estudios y la Declaración de Bolonia (1999), entre otros, justifican la importancia de analizar la lealtad en este ámbito (HENNING et al., 2001; HelGESEN y NESSET, 2007), necesaria para la supervivencia de las instituciones de enseñanza superior (HENNING et al., 2001; Helgesen y NESSET, 2007). Después de egresado, un alumno leal a la institución puede atraer nuevos alumnos a través de una comunicación boca-oreja positiva (Helgesen y Nesset, 2007), mejorar la imagen y reputación de la universidad en su entorno (MARTERSEN et al., 1999; NGUYen y Leblanc, 2001) o atraer entes $u$ organizaciones que hagan donaciones o financien proyectos de investigación (MAEL y ASHFORTH, 1992). De esta forma, se puede ver cómo las consecuencias de esta lealtad no se limitan al tiempo que permanece el alumno en la institución, sino que continúan a lo largo de su vida.

En el contexto de la educación superior existen pruebas empíricas que evidencian la influencia positiva de la imagen de la universidad en la satisfacción y en la lealtad (MARTENSEN et al., 1999; NGUYen y LEBLANC, 2001; BeErli et al., 2002; BeERli y DíAz, 2003). Específicamente, diversos estudios demuestran la fuerte influencia que puede ejercer la imagen positiva que pueda tener un alumno de una institución educativa a la hora de matricularse en ella (Bourke, 2000; CuBILlo et al., 2006).

Acorde a esto, y con la idea de aclarar las relaciones entre estas variables en el ámbito universitario, se propone la siguiente hipótesis:

$H_{3}$ : La imagen percibida por los egresados de la universidad influye directa y positivamente en la lealtad hacia la misma. 


\section{Modelo Teórico Propuesto}

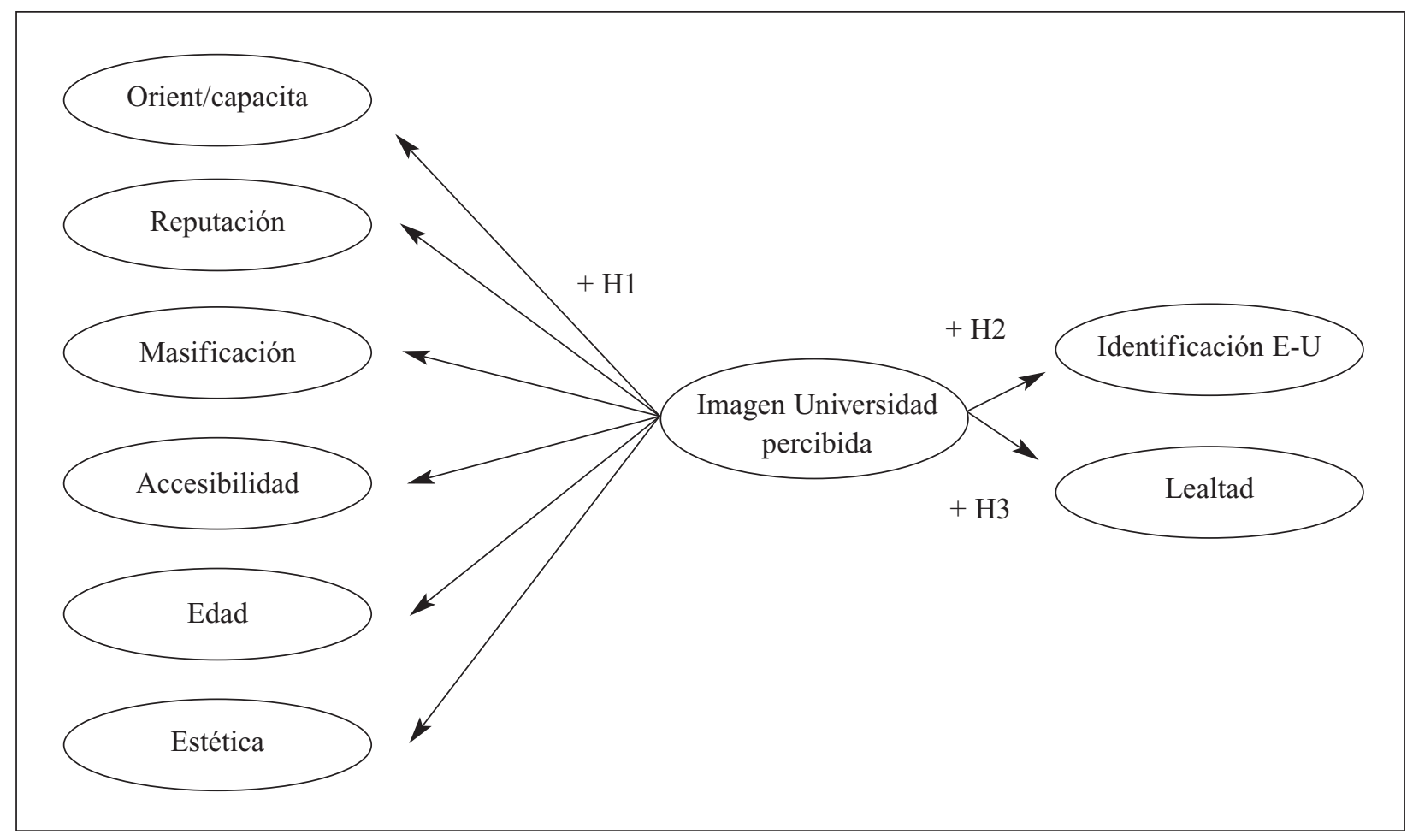

Fuente: Elaboración propia.

\section{METODOLOGÍA Y MEDICIÓN DE LAS VARIABLES}

Para llevar a cabo el contraste de las hipótesis propuestas y cumplir los objetivos de esta investigación, la población objetivo del estudio estuvo conformada por todos los individuos egresados de la Universidad de Valencia en los tres y dos años previos a la realización del trabajo de campo (2005 y 2006), en todas las titulaciones (en las áreas de Humanidades, Sociales, Experimentales, Salud y Técnicas) de primer y segundo ciclo. La muestra estuvo compuesta finalmente por 500 egresados.

Antes de la aplicación del instrumento, se realizaron varios pasos previos con la finalidad de evaluar y garantizar la idoneidad de la escala utilizada así como su adaptación al contexto de la investigación, entre ellos focus groups y pruebas piloto. Se entregó una versión preliminar a un conjunto de miembros de la comunidad universitaria que, por su experiencia y los puestos que ocupaban, pensamos que podrían ofrecer una opinión de valor sobre la misma (10 expertos participaron en esta etapa del focus group: 2 alumnos de último curso, 3 egresados, 1 personal de la universidad con experiencia en la elaboración de encuestas para alumnos, 2 catedráticos del área de comercialización e investigación de mercados; y 2 vicedecanos con responsabilidad en las relaciones con los alumnos). En segundo lugar, se realizaron dos aplicaciones piloto de la encuesta (en total 70 egresados universitarios de titulaciones del área de ciencias sociales, ciencias básicas, ciencias técnicas y humanidades) con el objeti- 
vo de verificar que las preguntas eran claras, que la aplicación no presentaba problemas, solventar algunos inconvenientes de la traducción y que la duración de la aplicación de la misma se ajustaba al tiempo estimado. Todas las opiniones recabadas de los distintos colectivos mencionados fueron aprovechadas para mejorar el cuestionario. Con todo ello se consiguió adecuar la presentación de escalas de forma idónea y ajustar los conceptos en un cuestionario definitivo que se podía responder fácilmente por tener una duración correcta y adecuada estructura.

La recogida de los datos, previa cesión de los mismos por la Universidad de Valencia para cumplir con la Ley de Protección de Datos, fue a través de entrevistas telefónicas asistidas por ordenador (sistema CATI) durante los meses de febrero-marzo de 2009. La selección de las unidades muestrales fue realizada mediante muestreo aleatorio simple.

Del conjunto de la muestra, el $68,4 \%$ fueron mujeres, y un $85 \%$ del total con edades comprendidas entre los 25 y 33 años. El 53\% obtuvo el título en el 2005 y el $64 \%$ egresó de una carrera de ciclo largo. El 78,6\% se encuentra trabajando, el 15,4\% está buscando trabajo y el $6 \%$ restante ni busca ni trabaja. El $40 \%$ tiene un salario entre 1200 y 1500 euros. En la muestra se encuentran representadas 57 de las 63 titulaciones que gestiona la Universidad, lo cual quiere decir que, a pesar de utilizar un muestreo aleatorio simple, se ha recogido la opinión de egresados de casi todas las titulaciones y de diferentes áreas.

La imagen de la universidad fue medida empleando la escala propuesta por BEERLI y DíAZ (2003), seleccionada por tener el mismo enfoque actitudinal de este trabajo y además porque ha sido validada en el ámbito de una universidad española, aunque en lugar de egresados, con alumnos. El objetivo es comprobar con procedimientos confirmatorios más rigurosos las propiedades psicométricas de esta escala y aplicar además un Análisis Factorial Confirmatorio (AFC) de segundo orden. Para ello, empleando una escala reflectiva, tal y como viene recogido generalmente en la literatura (Kazoleas et al., 2001; BeERLi y DíAz, 2003; ARPAN et al, 2003; LUQUE y DEL BARRIO, 2008), se definió una batería de veinticuatro ítems de imagen distribuidos en las seis dimensiones: cinco cognitivas y una afectiva propuestas por BEERLI y DíAz (2003) y descritas en el apartado 2.1.2. (ver tabla 2): 
TABLA 2

Escala de Medición de la Imagen Universitaria

\begin{tabular}{|l|l|l|l|}
\hline IOr1 & Es una universidad cercana a los alumnos. & IMas1 & Es una universidad que está poco masificada. \\
\hline IOr2 & $\begin{array}{l}\text { Es una universidad orientada y preocupada } \\
\text { por los alumnos. }\end{array}$ & IMas2 & $\begin{array}{l}\text { Estudiar en la UV tiene un coste bajo } \\
\text { (económicamente). }\end{array}$ \\
\hline IOr3 & Cuenta con un buen profesorado. & IMas3 & $\begin{array}{l}\text { Es una universidad que proporciona una } \\
\text { formación práctica. }\end{array}$ \\
\hline IOr4 & Es una universidad cercana a la sociedad. & IMas4 & Es una universidad muy exigente. \\
\hline IOr5 & $\begin{array}{l}\text { Es una universidad que proporciona una } \\
\text { buena formación. }\end{array}$ & IAcc1 & Es fácil entrar a estudiar en ella. \\
\hline IOr6 & Es una universidad cercana a las empresas. & IAcc2 & Es una universidad accesible para todos. \\
\hline IOr7 & Hay buen ambiente. & IEdad & Es una universidad joven. \\
\hline IOr1 & Es una universidad con prestigio. & Est1 & Es una universidad agradable. \\
\hline IR2 & Tiene una buena reputación. & Est2 & Es una universidad estimulante. \\
\hline IR3 & Es una universidad moderna. & Est3 & Es una universidad dinámica. \\
\hline IR4 & Cuenta con buenas instalaciones. & Est4 & Es una universidad alegre. \\
\hline IR5 & Cuenta con una amplia oferta de titulaciones. & & \\
\hline IR6 & Es una universidad innovadora. & & \\
\hline
\end{tabular}

Fuente: Adaptada de BeERLi y DíAz (2003).

Para la identificación egresado-universidad se utilizó la escala propuesta por MAEL y AsHFORTH (1992) y BHATTACHARYA et al. (1995), y para la lealtad se utilizaron 4 ítems adaptados de las escalas de MARTEnSEN et al. (1999) y
HENNING et al. (2001), como se puede ver en la tabla 3. En todos los casos se emplearon escalas tipo Likert de 11 puntos $(0=$ Totalmente en desacuerdo y $10=$ Totalmente de acuerdo). 
TABLA 3

Escala de Medición de identificación E-U y lealtad

\begin{tabular}{|l|l|}
\hline IEU1 & Cuando alguien critica a la UV te lo tomas como un insulto personal. \\
\hline IEU2 & Te interesa lo que piensa la gente sobre la UV. \\
\hline IEU3 & Cuando hablas de la UV normalmente dices "nosotros". \\
\hline IEU4 & Cuando la UV obtiene un éxito, sientes como si tú también hubieras tenido éxito. \\
\hline IEU5 & Cuando alguien elogia la UV, te lo tomas como un cumplido personal. \\
\hline IEU6 & Te incomoda que alguna noticia de un medio de comunicación critique a la UV. \\
\hline L1 & $\begin{array}{l}\text { Si tuvieras que realizar otros cursos, conferencias o estudios de mejora profesional seguramente conside- } \\
\text { rarías a la UV como primera opción. }\end{array}$ \\
\hline L2 & Si alguien te pide consejo recomendarías la UV. \\
\hline L3 & Si se te presenta la oportunidad, comentarías con tus amigos y familiares cosas positivas de la UV. \\
\hline L4 & Animarías a familiares y amigos a que estudiasen en esta Universidad. \\
\hline
\end{tabular}

\section{ANÁLISIS DE LOS RESULTADOS}

Tras haber especificado las características metodológicas de la investigación a realizar, e iniciada la depuración de las escalas empleadas a través del proceso de pretest, se procede en este epígrafe a detallar los resultados de la investigación obtenidos en el estudio empírico. Con esta finalidad, y siguiendo el procedimiento en dos pasos recomendado por ANDERSON y GERBING (1988), se analiza primero la calidad de las medidas de los constructos a través de una AFC, estimando en primer lugar el llamado modelo de medida de la variable imagen de la universidad y, en segundo, el modelo de estructura de covarianzas o modelos de ecuaciones estructurales (MEC). Para tal fin, se utilizaron los paquetes estadísticos SPSS 12 (SPSS, 19892003) y EQS 6,1 (BENTLER, 1985-2005).

En este sentido y siguiendo los MEC, se plantea la construcción de un factor de segundo orden a partir de los componentes considerados, determinándose la bondad de este modelo de medición, que refleja la multidimensiona- lidad de la imagen de la universidad para los egresados y sus posibles efectos en la identificación E-U y lealtad.

Para la realización del AFC se optó por el método de estimación de Máxima Verosimilitud Robusto (MVR), puesto que es un método adecuado cuando no se da la condición de normalidad univariante y multivariante de los datos (HAIR et al., 2005), como es el caso.

\subsection{Evaluación de las propiedades psicométricas del modelo de medida}

Como punto de partida, considerando las respuestas obtenidas a la batería de ítems que componen la escala diseñada sobre imagen percibida, el cálculo de las correlaciones ítemimagen total de forma aislada para cada componente permitió eliminar aquellas variables observadas cuyo valor era inferior a $0,35^{3}$. Esto ocurrió para los ítems primero y segundo de la dimensión de "masificación". Las variables latentes incluidas en este análisis son: orienta- 
ción y capacitación de la universidad, reputación e innovación ${ }^{4}$, masificación, accesibilidad, edad e imagen estética-afectiva ${ }^{5}$, componentes todos ellos que explican la naturaleza de la imagen, las primeras cinco de naturaleza cognitiva y la sexta de naturaleza afectiva.

Partiendo de un modelo a priori de la estructura del cuestionario fundamentado tanto en razones teóricas como en factoriales exploratorios realizados en otras muestras y, dada la aproximación confirmatoria de este estudio en el que la exploración de los datos queda en segundo plano, la cuestión más crítica es la evaluación del ajuste del modelo a los datos. Recibe así una mayor atención la elección de los mejores índices de ajuste global disponibles en el contexto del AFC.

El proceso de evaluación de la escala utilizada a través de la fiabilidad y validez de los conceptos introducidos en el modelo se llevó a cabo a través de un AFC de primer orden. De acuerdo a los resultados obtenidos, a pesar que todos los ítems cargan en su concepto de forma significativa $(\mathrm{p}<0,01)$, se puede mejorar la bondad del ajuste planteado. De este modo, atendiendo a los índices de modificación, el Test de Lagrange y a los residuos estandarizados, éstos sugirieron que para mejorar significativamente el ajuste, algunos indicadores debían cargar sobre otro factor y otros ser eliminados; en este sentido se eliminaron algunos ítems que permitieron mejorar el ajuste del modelo, al aumentar el valor de los índices y disminuir los valores de los indicadores chi-cuadrado, chi-cuadrado normada y RMSEA.

Asimismo, el factor "edad" conformado por un solo indicador presentó problemas de validez discriminante con el factor "estética-afectiva" al tener una correlación de 0,998. El Test de Lagrange sugirió que cargara en ese factor, revelando la existencia de una relación fuerte entre el único ítem de la dimensión "edad" y los ítems que componen la dimensión denominada "estética-afectiva". Ellos parecen tener, según los resultados de esta prueba, algún tipo de covariación adicional. Dado que la mejora esperada del ajuste del modelo era sustancial, y que el sentido teórico de la propuesta de unión es sustentable, puesto que otras escalas de imagen (AAKER, 1997; GARCÍA DE LOS SALMONES, 2001) proponen la imagen de juventud como parte de la dimensión afectiva, más relacionada con la personalidad de marca, visto como el componente emocional de la imagen, se pasó a unir ambos factores y así permitir al modelo dar cuenta de esa importante fuente de covariación.

Con respecto a la dimensión de masificación, el Test de Lagrange también indicó la existencia de una covariación adicional con la dimensión "orientación y capacitación", dado que la mejora era sustancial y como en el caso anterior teóricamente es sustentable esta unión puesto que los ítems "proporciona una capacitación práctica" y "es una universidad muy exigente" están relacionados más con la dimensión "orientación y capacitación" que con la dimensión original "masificación", se unieron estos dos indicadores a la dimensión 1, eliminando la dimensión de "masificación".

Finalmente, el análisis proporcionó una solución de cuatro dimensiones, tras haber planteado en el modelo teórico seis, estas cuatro coincidentes con las propuestas en la teoría: tres dimensiones de carácter cognitivo F1: "orientación y capacitación de la universidad"; F2: "reputación e innovación"; F3:“accesibilidad” y una dimensión de carácter afectivo, F4:"estéticaafectiva". Los indicadores eliminados fueron: de la dimensión 1: Or1 (es una universidad cercana

\footnotetext{
3 Aunque los límites varían según los autores, NoRusis (1992) sugiere que el valor mínimo aceptable para garantizar la robustez de una escala es una correlación ítem-total de 0,3, mientras que SAXE y WeITZ (1982) establecen un valor mínimo de 0,35.

${ }^{4}$ En el modelo propuesto por BEERLI et al. (2002) se le denomina "reputación"; sin embargo como también incluye aspectos de modernidad, innovación e instalaciones, se decidió llamarla "reputación e innovación". De esta manera, el nombre es más apropiado a los ítems que engloba.

${ }^{5}$ En el modelo propuesto por BEERLI et al. (2002) se le denomina componente afectivo, sin embargo aquí se le ha denominado: imagen estética-afectiva, tomando en cuenta otros estudios que también denominan de esa forma al componente afectivo o emocional de la imagen (GARCíA DE LOS SALMONES, 2001).
} 
a los alumnos) y Or7 (hay buen ambiente); de la dimensión 2: R1 (es una universidad con prestigio) y R5 (cuenta con una oferta amplia de titulaciones); y de D5: Af2 (es una universidad estimulante) y Af3 (es una universidad dinámica).

Con dichas modificaciones, las medidas de bondad de ajuste del modelo de medida mejoran notablemente y cumplen de una manera global los valores críticos de aceptación, demostrando un ajuste aceptable del modelo.
El ajuste del modelo propuesto fue evaluado mediante los índices: S-B $\chi 2$, BBNFI, $\chi 2$ normada, CFI, IFI y RMSEA. Asimismo, en la escala final obtenida, todos los coeficientes estandarizados cargan en su concepto de forma significativa $(p<0,01)$. En la tabla 4 aparecen los principales indicadores de bondad de ajuste del modelo de medida, así como los valores de los s indicadores calculados para constatar las propiedades psicométricas del mismo.

TABLA 4

Resultados del Análisis Factorial Confirmatorio. Propiedades psicométricas del instrumento de medida

\begin{tabular}{|c|c|c|c|c|c|c|c|c|}
\hline \multirow[b]{2}{*}{ FACTOR } & \multirow[b]{2}{*}{ ÍTEMS } & \multicolumn{2}{|c|}{ Validez Convergente } & \multicolumn{3}{|c|}{ Fiabilidad } & \multicolumn{2}{|c|}{ Validez discriminante } \\
\hline & & $\lambda$ (ce) & $\begin{array}{c}\text { Promedio } \\
\text { cargas }\end{array}$ & $\begin{array}{c}\alpha \\
\text { Cronbach }\end{array}$ & IFC & IVE & $\begin{array}{l}\text { Mayor correl } \\
\text { entre factores }\end{array}$ & $\begin{array}{r}\text { Inter. } \\
\text { Confianza/ } \\
\mathrm{S}-\mathrm{B} \chi^{2}(\mathbf{g l}) \\
\mathbf{M r}^{* *} \\
\end{array}$ \\
\hline \multirow{7}{*}{$\begin{array}{c}\text { F1 } \\
\text { ORIENTACIÓNY } \\
\text { CAPACITACIÓN }\end{array}$} & ImcOr2 & $0,735^{* *}$ & \multirow{7}{*}{0,667} & \multirow{7}{*}{0,84} & \multirow{7}{*}{0,90} & \multirow{7}{*}{0,58} & \multirow{26}{*}{$\begin{array}{c}\text { F1-F6 } \\
0693(0,027)\end{array}$} & \multirow[t]{26}{*}{$0,627-0,759$} \\
\hline & ImcOr3 & $0,763 * *$ & & & & & & \\
\hline & ImcOr4 & $0,743 * *$ & & & & & & \\
\hline & ImcOr5 & $0,802 * *$ & & & & & & \\
\hline & ImcOr6 & $0,517 * *$ & & & & & & \\
\hline & Mas3 & $0,499 * *$ & & & & & & \\
\hline & Mas4 & $0,612 * *$ & & & & & & \\
\hline F2 & ImcR2 & $0,735 * *$ & \multirow{4}{*}{0,69} & \multirow{4}{*}{0,86} & \multirow{4}{*}{0,86} & \multirow{4}{*}{0,61} & & \\
\hline REPUTACION & ImcR3 & $0,763 * *$ & & & & & & \\
\hline & ImcR4 & $0,743 * *$ & & & & & & \\
\hline & ImcR6 & $0,517 * *$ & & & & & & \\
\hline \multirow[t]{2}{*}{$\begin{array}{c}\text { F3 } \\
\text { ACCESIBILIDAD }\end{array}$} & ImcAcc1 & $0,763 * *$ & \multirow{2}{*}{0,877} & \multirow{2}{*}{0,87} & \multirow{2}{*}{0,93} & \multirow{2}{*}{0,86} & & \\
\hline & ImAcc2 & $0,990 * *$ & & & & & & \\
\hline \multirow{3}{*}{$\begin{array}{c}\text { F4 } \\
\text { ESTÉTICA-AFECTIVA }\end{array}$} & Est1 & $0,772 * *$ & \multirow{3}{*}{0,839} & \multirow{3}{*}{0,91} & \multirow{3}{*}{0,93} & \multirow{3}{*}{0,82} & & \\
\hline & Est4 & $0,938 * *$ & & & & & & \\
\hline & Edad & $0,807 * *$ & & & & & & \\
\hline \multirow{6}{*}{$\begin{array}{c}\text { F5 } \\
\text { IDENTIFICACIÓN E-U }\end{array}$} & IEU1 & $0,770 * *$ & \multirow{6}{*}{0,847} & \multirow{6}{*}{0,93} & \multirow{6}{*}{0,97} & & & \\
\hline & IEU2 & $0,811 * *$ & & & & & & \\
\hline & IEU3 & $0,787 * *$ & & & & 0,82 & & \\
\hline & IEU4 & $0,916^{* *}$ & & & & & & \\
\hline & IEU5 & $0,929 * *$ & & & & & & \\
\hline & IEU6 & $0,867 * *$ & & & & & & \\
\hline & $\mathrm{L} 2$ & $0,830 * *$ & & & & & & \\
\hline F6 & $\mathrm{L} 3$ & $0,946^{* *}$ & & & & & & \\
\hline & L4 & $0,940 * *$ & 0.924 & 0.91 & 0.98 & 0.91 & & \\
\hline & L5 & $0,979 * *$ & & & & & & \\
\hline$* * p<0,01$ BONDAD DEI & USTE M & & & & & & & \\
\hline $\mathrm{S}-\mathrm{B} \chi^{2}(257)=648,692$ & 0,000 & BBNI & 0,92 & $0,93 \quad \mathrm{IFI}=0$ & $3 \mathrm{RN}$ & $A=0$ & $\chi^{2} /$ g.l. $=2,5$ & \\
\hline
\end{tabular}

$\mathrm{Mr}=$ Modelo restringido. 
Como se observa en la tabla 3, los indicadores utilizados para la evaluación de la fiabilidad del instrumento de medida superan sus correspondientes valores críticos para cada uno de los seis factores analizados. Con respecto a la validez convergente del modelo de medida, los criterios utilizados para constatar su cumplimiento fueron dos: primero, el hecho de que todas las cargas factoriales de las variables observadas sean significativas y, segundo, que el promedio de dichas cargas factoriales estandarizadas sea superior a 0,7 (HAIR et al., 2005). En la tabla 3 se puede verificar cómo ambas condiciones se cumplen. Por último, se verifica el cumplimiento de la validez discriminante a través de dos criterios: el test del intervalo de confianza, como se ve en la tabla el intervalo entre los factores que tienen mayor correlación (F1 y F6) no incluye el 1, y el test de la varianza extraída, que arrojó resultados satisfactorios para todos los factores dado que los cuadrados de las correlaciones entre los pares de factores son menores que los AVE de cada uno de los factores que los componen.

En consecuencia, tras el análisis de la bondad del ajuste y de las propiedades psicométricas de la escala, el modelo de medida de la variable imagen quedó finalmente compuesto por cuatro dimensiones y diecisiete ítems, estructurados como se refleja en la Figura 2. Las otras dos variables que componen el modelo quedaron igual, identificación E-U con 6 indicadores y lealtad con 5 , ambas variables unidimensionales.

FIGURA 2

Modelo de medición de la imagen de la universidad (escala final)

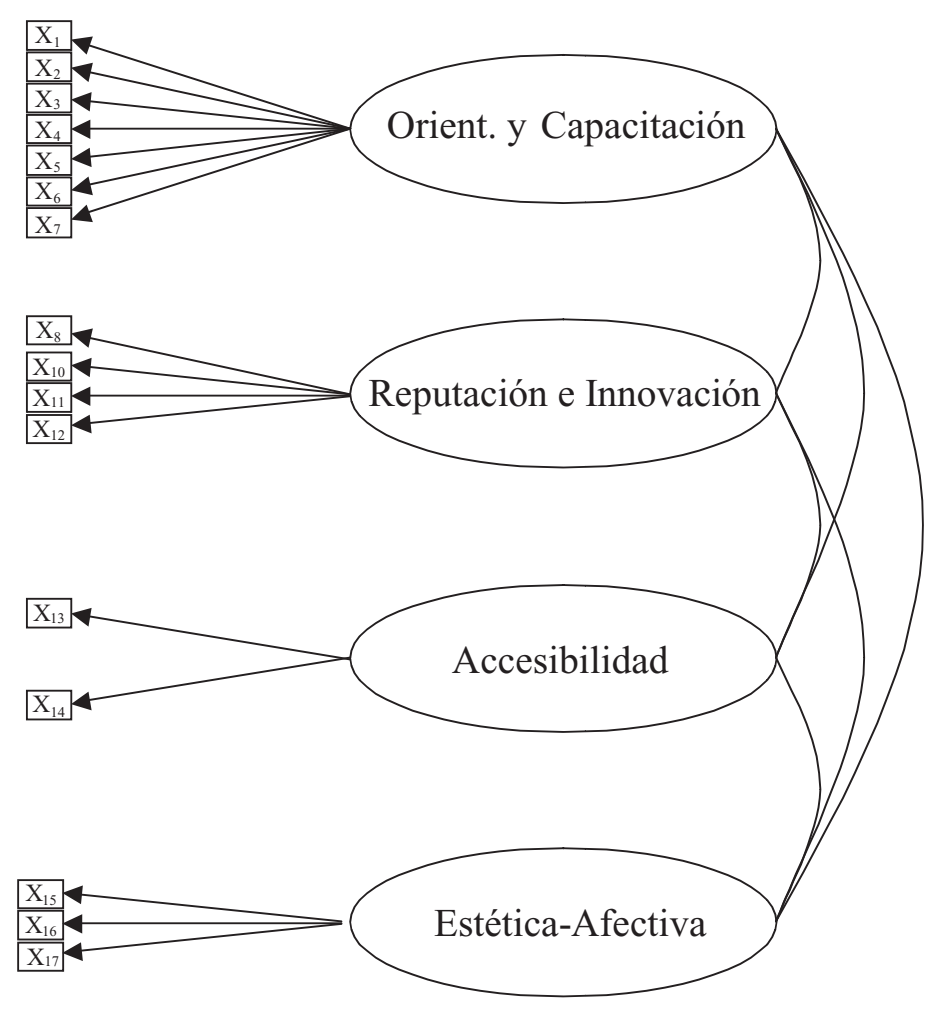


Una vez analizadas las propiedades psicométricas de los componentes de la imagen de la universidad, de la identificación y lealtad, la propuesta se encamina hacia la construcción de un modelo de medida multidimensional en el que se puedan confirmar las relaciones reflectivas subyacentes entre el concepto, sus dimensiones y los efectos sobre la lealtad e identificación E-U. Se trata, por tanto, de analizar la conveniencia de especificar un factor de segundo orden en el que, en lugar de poder medir de forma directa la imagen percibida, ésta se determine a través de las dimensiones que lo componen.

Para la estimación de este modelo, se ha llevado a cabo un AFC de segundo orden. Los resultados, que han sido recogidos en la tabla 5, indican una adecuada fijación de la especificación de segundo orden para la medida de la imagen percibida de la universidad. Se observa cómo los valores de los parámetros gamma $(\gamma)$ soportan de forma significativa $(\mathrm{p}=0,001)$ la relación reflectiva entre el concepto de imagen y sus dimensiones. Sin embargo, indican que el peso de la dimensión orientación y capacitación, perteneciente al componente cognitivo, es el más elevado, seguidos casi con el mismo peso de las dimensiones reputación e innovación y estética-afectiva. La accesibilidad, por su parte, parece tener menos importancia entre los egresados.

TABLA 5

Resultados del modelo estructural

\begin{tabular}{|c|c|c|c|c|}
\hline Hipótesis & Relación estructural planteada & & $\lambda$ & Resultado \\
\hline $\mathrm{H}_{1}$. & Dimensión Orient. y capac $\leftarrow$ Imagen & & $0.924^{* *}$ & Aceptada \\
\hline $\mathrm{H}_{1}$. & Dimensión Reput e Innovac $\leftarrow$ Imagen & & $0.664^{* *}$ & Aceptada \\
\hline $\mathrm{H}_{1}$. & Dimensión Accesibilidad $\leftarrow$ Imagen & & $0.351^{* *}$ & Aceptada \\
\hline $\mathrm{H}_{1}$. & Dimensión Estética-afectiva $\leftarrow$ Imagen & & $0,628^{* *}$ & Aceptada \\
\hline $\mathrm{H}_{2}$. & Imagen $\rightarrow$ Identificación E-U & & $0,470^{* *}$ & Aceptada \\
\hline $\mathrm{H}_{3}$ & Imagen $\rightarrow$ Lealtad & & $0,738^{* *}$ & Aceptada \\
\hline \multicolumn{5}{|c|}{ Indicadores de bondad de ajuste } \\
\hline \multicolumn{5}{|c|}{ S-B $\chi^{2}(293 \mathrm{gl})=737.217 * *(p=0,000)$} \\
\hline & BBNNFI & CFI & IFI & RMSEA \\
\hline & 0.92 & 0.92 & 0.92 & 0.05 \\
\hline
\end{tabular}

$* * \mathrm{p}<0,01$.

Nuevamente el ajuste del modelo propuesto fue evaluado mediante los índices: $\mathrm{S}-\mathrm{B} \chi 2$, NNFI, CFI, IFI y RMSEA, los cuales proporcionaron valores globalmente aceptables. Debido a que todos los ítems cargan significativamente en su dimensión, y que las medidas de ajuste absoluto, incremental y de parsimonia se encuentran dentro de los límites considerados como indicativos de un ajuste adecua- do, estos resultados son indicativos de la conveniencia de plantear un modelo multidimensional de la imagen de la universidad percibida por los egresados, donde este concepto sea medido a través de sus dimensiones reflectivas, esto es, orientación y capacitación, reputación e innovación, accesibilidad y estética-afectiva, con lo cual queda confirmada la Hipótesis 1 propuesta. 
En segundo lugar, como se desprende de la lectura de la misma tabla, los resultados del análisis sugieren que las relaciones estructurales establecidas en las hipótesis $\mathrm{H} 2$ y $\mathrm{H} 3$ son significativas para un nivel de $\mathrm{p}<0,01$; por lo que no es posible su rechazo y en consecuencia han sido aceptadas.

\section{DISCUSIÓN DE RESULTADOS Y CONCLUSIONES}

En primer lugar, los resultados obtenidos en este estudio suponen una aportación de utilidad en la investigación sobre la medición de la imagen corporativa, específicamente sobre la imagen de una institución pública como lo es la Universidad, más allá de lo que ha sido realizado hasta el momento en la literatura, así como de su influencia en dos variables de relevancia como la identificación y lealtad. De este modo, a partir del análisis de una serie de corrientes de investigación y del análisis crítico de las mismas, se decidió tomar como base la propuesta original de BEERLI y DíAz (2003) para el desarrollo del modelo conceptual de medición de la imagen, pues se trata, a nuestro juicio, de aquella estructura que refleja en mejor medida la compleja naturaleza de la imagen de la universidad, además aplicada en el mismo ámbito de este estudio, el español.

En esta línea, tal y como señala la revisión de la literatura, muchos autores han planteado la multidimensionalidad de la imagen (KAZOLEAS et al., 2001; García DE LOS SALMONES, 2001; Alessandri et al., 2006; CERVERA et al., 2008), algunos a través de modelos causales, determinando la relación de cada una de las dimensiones sobre la imagen global (LANDRUM et al., 1998; BEERLI et al., 2002; ARPAN et al., 2003; LUQUe y DEL BARRIO, 2008). Pero hasta donde se tiene conocimiento, no se ha realizado hasta el momento un tratamiento de la imagen desde una perspectiva multidimensional con dimensiones cognitivas y afectivas y un factor de orden superior, lo cual permite analizar la influencia de otras variables en la imagen de una manera global, y en posteriores estudios el impacto de ella sobre otras.

El proceso de validación de la escala de imagen, proporcionó como resultado la eliminación de algunos indicadores $\mathrm{y}$, como consecuencia, de dos dimensiones, situación que se considera conveniente justificar. En primer lugar, se eliminó la dimensión referente a la masificación, compuesta por cuatro indicadores. Dos de ellos referentes al hecho de que la universidad está poco masificada y tiene un coste económicamente bajo, se eliminaron por su baja correlación ítem-total. La razón de este hecho puede deberse a que, frente a otros elementos que influyen en la formación de la imagen, estos dos no son tan relevantes bajo la percepción de los egresados en la actualidad. En relación a la masificación, según datos estadísticos de la Universidad de Valencia para los períodos académicos desde el 2002-03 hasta el 2005-06 (durante los cuales cursaron sus estudios la mayoría de los encuestados), la relación alumno/profesor se sitúa en 14 aproximadamente. Con este dato se podría suponer que la masificación no es un factor relevante en este contexto para la formación de la imagen, situación que tal vez en otras universidades como en la que se validó la escala podría ser diferente para ese momento, pero que en la actualidad puede resultar un factor no relevante en el contexto del EEES y las metodologías de innovación docente que supone.

Además, en la revisión de la literatura sobre la medición de la imagen de la universidad, fueron aspectos que no se incluyeron en ninguna de las dimensiones de las escalas propuestas por otros autores (TRAVERSO y ROMÁn, 2007; AlesSANDRI et al., 2006; CuBILlo et al., 2006; ARPAN et al., 2003) con excepción del estudio de KAZOLEAS et al. (2001), quienes incluyeron aspectos financieros. Sin embargo, los resultados no revelan una gran influencia de este aspecto sobre la formación de la imagen en comparación con los demás indicadores. Los otros dos ítems referentes al hecho de que la universidad 
es exigente y práctica en cuanto a su capacitación, se consideró adecuado incluirlos en la dimensión "orientación y capacitación", por estar relacionados con este contenido.

Siguiendo con la validación, además se hizo un ajuste entre la dimensión "edad" y la "estética-afectiva". Puesto que estadísticamente el único indicador de la dimensión "edad" presentaba una alta correlación con esta dimensión, se decidieron unir ambas dimensiones en una sola. Otra de las razones fue el hecho de que la media de este indicador es de 6,93 (en una escala del 0 al 10) y, teniendo en cuenta que la Universidad de Valencia no es una universidad joven objetivamente, ya que se fundó en el año 1502, se puede deducir el hecho de que la percepción de juventud de la universidad viene desde el punto de vista emocional-afectivo. Asimismo, como ya se mencionó anteriormente, otras escalas de imagen (AAKER, 1997; GARCÍA DE LOS SALMONES, 2001) proponen la imagen de juventud como parte de la dimensión afectiva, más relacionada con la personalidad de marca, visto como el componente emocional de la imagen. Asimismo, fue necesario eliminar un indicador de la dimensión "orientación y capacitación" (es una universidad cercana a los alumnos) y otro de la dimensión "reputación e innovación" (es una universidad con prestigio), que en estos casos no se consideró problema, puesto que dentro de ambas dimensiones había otros indicadores que recogían de alguna manera aquellos que fueron eliminados.

Tras la validación de la escala de imagen, se concluye que a través de esta investigación se ha evidenciado empíricamente la conveniencia de una estructura multidimensional compleja que mida el concepto de imagen de la universidad percibida por los egresados. La composición original de seis dimensiones, ha sido finalmente estructurada en cuatro - esto es, orientación y capacitación, reputación e innovación, accesibilidad y estética-afectiva- y quince indicadores, como resultado de una aproximación más operativa a la riqueza y complejidad de la imagen percibida.
A través de esta propuesta multidimensional, se ha corroborado la idea de que considerar componentes cognitivos y afectivos de la imagen van adquiriendo un mayor protagonismo doctrinal en la medida en que los trabajos empíricos cuyo objeto de estudio se centraban en actitudes y creencias (CAPRIOTTI, 2006; COSTA, 2001; ARPAN et al., 2003) superan el modelo unidimensional propuesto por FISHBEIN y AJZEN (1975). En el marco de esta composición, aspectos como cercanía a la sociedad, cercanía a los alumnos y a las empresas (incluidos en la dimensión de orientación y capacitación) así como aspectos relacionados con el espíritu joven y alegre de la universidad (incluidos en la dimensión estética-afectiva) subyacen como partes importantes que componen la noción de imagen de la universidad para el egresado. Esta aproximación empírica al carácter abstracto de la imagen está en consonancia con lo manifestado a nivel teórico por diversos autores (CAPRIOTTI, 2006; PARAMESWARAN y GlowACKA, 1995; LUQUE Y DEL BARRIO, 2008).

Del análisis realizado se desprende que la dimensión de orientación y capacitación parece ser la más importante en la formación de percepciones sobre la imagen de la universidad de los egresados, seguida casi con el mismo peso por la dimensión de reputación e innovación y luego la estética-afectiva. Este hallazgo es consistente con estudios como el de Williams y MoffiTT's (1997) y Kazoleas et al. (2001) en el que concluyeron que aquellos aspectos que puede controlar la organización (emisor) tienen un gran impacto en la imagen percibida de los que reciben esa imagen (receptores). Asimismo, también se encuentran estos resultados en la línea de otras investigaciones que han demostrado el efecto predominante de aspectos relacionados directamente con el servicio (calidad y características de la formación, la docencia) y la orientación hacia sus diferentes stakeholders (empresa, sociedad, alumnos) en la imagen institucional (LANDRUM et al., 1998; ARPAN et al., 2003; BeERLi y DíAz, 2003; LuQue y DEL BARrio, 2008, CERVERA et al., 2011). 
Así, al igual que KotLer y ANDREASEN (1996) y CERVERA et al. (2008), consideramos que las instituciones sin ánimo de lucro deben adoptar prácticas de gestión empresarial $\mathrm{y}$, por ello, la medición de su imagen y la evaluación de su posicionamiento resultan fundamentales para captar los recursos económicos y humanos que precisan para su correcto funcionamiento. Si bien los consumidores están cada vez más informados y son más exigentes (GUARDIA, 1998), entendemos que la identificación de los factores determinantes de la imagen corporativa suponen un primer paso hacia la construcción de una imagen favorable de las organizaciones sin ánimo de lucro y la definición de su posicionamiento con respecto a su competencia.

Asimismo se ha considerado oportuno proponer consecuencias de la imagen de la universidad por considerarse una contribución a este campo. La aceptación de las hipótesis 2 y 3 confirman hallazgos previos obtenidos fundamentalmente en otros ámbitos muy diferentes al de la universidad, demostrando que la imagen ejerce una influencia directa y positiva en la identificación y la lealtad del egresado para con su institución, siendo mayor la influencia en la lealtad que en la identificación. Como aportación a la nueva perspectiva de análisis de relaciones organización-consumidor, se ha demostrado que el análisis de este tipo de relaciones no se basa estrictamente en la identificación del consumidor con la empresa, como elemento resumen de toda la capacidad de atracción de la empresa para el consumidor, sino que esta identificación es un complemento que puede aportar una mayor capacidad explicativa de estas relaciones.

Dado que la imagen se conforma a través de cuatro dimensiones -tanto cognitivas como afectivas- que en conjunto influyen sobre la lealtad y la identificación E-U, es importante que los responsables de las universidades pongan un mayor énfasis en el desarrollo de políticas tanto de comunicación como de gestión que incidan en aquellos atributos que más influyen en la conformación de esa imagen por parte de los egresados, y que hacen referencia a factores relativos a la "orientación y capacitación de la universidad", a la "reputación e innovación" y a la imagen "estética-afectiva". De esta forma, la imagen de marca de la universidad se fundamentará en bases sólidas y relevantes para sus egresados, influyendo directamente en sus niveles de identificación para con la institución, siendo capaces de defenderla y sentirse parte de ella, así como en los niveles de lealtad, con lo cual aumentará la intención de elegirla de nuevo para estudios de postgrado, seguir en contacto con ella, recomendarla o hablar bien de ella en su entorno.

Sin embargo, los resultados y conclusiones derivados del estudio empírico deben matizarse atendiendo a una serie de limitaciones que, a nuestro juicio, presenta esta investigación. En primer lugar, el modelo ha sido contrastado basándose en las opiniones de los egresados en un período específico del tiempo y de una universidad española en particular. Esto provoca que la generalización de algunos de los mismos se vea limitada a los supuestos que subyacen en el ámbito de investigación examinado, por lo que se recomienda extender este estudio a otras universidades y comparar los resultados, validando así el instrumento en otras instituciones y países. Asimismo, sería de gran interés que en futuras investigaciones se llevasen a cabo estudios longitudinales que contemplaran las posibles variaciones a lo largo del tiempo en sus percepciones, para determinar si influye de alguna manera.

Asimismo, aún sigue sin haber consenso respecto a qué dimensiones tiene el constructo imagen, pudiendo estar sujeto al grupo de interés que esté percibiendo esta imagen, puesto que las dimensiones percibidas por los egresados pueden no coincidir con las de los profesores o empresas (LUQUE y DEL BARRIO, 2008). Esta escala propuesta y adaptada se ha mostrado válida en el ámbito de los egresados. Por otro lado, la propia naturaleza del concepto de imagen, muy sensible a los efectos del contexto sociocultural, del tipo de organización y del público que la esté evaluando (KAZOLEAs et al., 
2001), demanda cautela en la traslación de los resultados y conclusiones a otros grupos de interés para la universidad como a otros entornos distintos del español.

Finalmente, las conclusiones y limitaciones de esta investigación, junto a la naturaleza del propio fenómeno objeto de estudio, permiten el desarrollo de posteriores trabajos a través del planteamiento de nuevas líneas de investigación. La validación de esta escala y el planteamiento de consecuencias de la variable es el inicio para futuras investigaciones que incluyan otras variables relacionadas en este ámbito.

En sintonía con lo señalado por diversas investigaciones relacionadas con el hecho que la forma en que una organización lleva las interacciones con sus stakeholders tiene una fuerte influencia en la imagen que ellos perciben de la organización (BITNER, 1992; NGUYEN et al., 2004, CERVERA et al., 2011), resultaría interesante analizar el papel crucial que tiene el profesorado en el proceso de formación de la imagen durante su contacto con los alumnos, específicamente durante este particular "encuentro de servicio". De esta manera, se confirmaría la importancia de la relación alumno-profesor como uno de los elementos esenciales del servicio de educación.

Otra variable a nuestro juicio de interés, sería analizar el papel que tiene la satisfacción del egresado en referencia a su experiencia de servicio, como ya se ha realizado en otros estudios (BeEli y Díaz, 2003; MARTENSEN et al., 1999; Alves y RAPOSO, 2004; MARZO et al., 2005; HELGENSEN y NeSSET, 2007) para, de este modo, lograr que los alumnos cubran o incluso superen las expectativas que tienen al ingresar en la universidad. Esto influiría directamente en la imagen percibida de la universidad y quizás en otras variables como el compromiso, la confianza o el valor percibido del servicio (MARTENSEN et al., 2000; Marzo et al., 2005; HelgeSEn y NesSET, 2007). Finalmente, invitamos a replicar el modelo propuesto en otras universidades y también con otros stakeholders tales como alumnos, empresas o la sociedad en general.

\section{REFERENCIAS BIBLIOGRÁFICAS}

AAKer, J. (1997). "Dimensions of Brand Personality", Journal of Marketing Research, 34(3), 347-357.

Ahearne, M; Bhattacharya, C. y Gruen, T. (2005). "Antecedents and Consequences of Customer-Company Identification:Expanding the Role of Relationship Marketing", Journal of Applied Psychology, 90, (3), 574-585.

Alessandri, S.; YAnG, S. y Kinsey, D. (2006). "An Integrative approach to university visual identity and reputation", Corporate Reputation Review, 9 (4), 258-270.

ANDERSON, J.; GERBING, D. (1988). "Structural Equation Modeling in Practice: A Review and Recommended Two-Step Approach", Bulletin, Psychological Vol. 103(3), 411-423.

ARPAN, L.; RANEY, A. y ZivNUSKA, S. (2003). "A cognitive approach to understanding university image", Coporate Communications: An International Journal, vol. 8 (2), 97-113.

BAgOzZI, R. y BurnKrant, R. (1985). "Attitude organization and the attitude-behavior relation: a reply to DilJon and Kumar", Journal of Personality and Social Psychology, 49, 47-57.

BARICH, H. y Kotler, P. (1991). “A framework for marketing image management", Sloan Marketing Review, Vol. 32 (2), 94-104.

BeErli, A.; Díaz, G. y Pérez, P. (2002). “Configuración de la imagen de las universidades a través de los componentes cognitivo y afectivo", Cuadernos Aragoneses de Economía, Vol. 12(2), 337-352.

BeErli, A. y Díaz, G. (2003). "Los Efectos de la Imagen Percibida de la Universidad en la Satisfacción de los Estudiantes", Revista Española De Investigación y Marketing ESIC, Marzo 2003, 7- 35.

Bentler, P. (2005). EQS 6: Structural Equation Program Manual. Encino, CA: Multivariate Software.

Bergami, M. y BAGOzZI, R. (2000). "Self-categorization, affective commitment and group 
self-esteem as distinct aspects of social identity in the organization", British Journal of Social Psychology, 39, 555-577.

Bhattacharya, C.; RaO, H. y Glynn, M. (1995). "Understanding the Bond of Identification: An Investigation of Its Correlates Art Museum members», Journal of Marketing, 59(4), p.46-57.

BhatTaCHARYa, C. y Elsbach, K. (2002). "Us versus them: the roles of organizational identification and disidentification in social marketing initiatives". Journal of Public Policy \& Marketing, 21(1), 26-36.

Bhattacharya, C. y Sen, S. (2003). "Consumer-Company Identification: A Framework for Understaning Consumers' Relationships with Companies", Journal of Marketing, 67(2), 76-88.

Bitner, M. (1992). "Servicescapes: The Impact of Physical Surroundings on Customers and Employees", Journal of Marketing, 56 (Abril), 57-71.

Boorstin, D. (1977). The Image, Atheneum, Nueva York.

Bourke, A. (2000). "A model of the determinants of international trade in higher education", The Service Industries Journal, 20 (1), 110-138.

CAPRIOTTI, P. (2006). La Imagen de Empresa. Estrategia para una comunicación integra$d a$, El Ateneo, Barcelona, [versión online, 2006, en http://www.bidireccional.net].

Carmeli, Gilat, G. y Weisberg, J. (2006). "Perceived External Prestige, Organizational Identification and Affective Commitment: A Stakeholder Approach", Corporation Reputation Review, 9 (1), 92-104.

CARrillo, V. y RuaO, T. (2005). “La reputación en las Universidades: de la Identidad Local a la Reputación Europea", Actas del V Congresso de Comunicação Local, Universitat Jaume I De Castellón, España, 14-16 de Diciembre de 2005.

Cervera, A.; Ruiz, M. y Kleefeldt, B. (2008). "Aplicabilidad de los conceptos de imagen corporativa y posicionamiento a las ONGD", ponencia presentada en el VII Congreso Inter- nacional de Marketing Público y No Lucrativo" 12-13 de junio de 2008, Szeged, Hungría.

Cervera, A.; Schlesinger, W.; Iniesta, M.A.; SÁNCHEZ, R. (2011). "Un enfoque de stakeholders para la configuración de las universidades como centros de formación a lo largo de la vida de los individuos: aplicación a los egresados", Revista Europea de Dirección y Economía de la Empresa, 20 (4), 97-116.

CHeli, E. (1992). La realtà mediata. La influenza dei mass media tra persusione e construzione sociale della realità. Milano:Francoangeli.

Cornwell, B. y CoOte, L. (2005). "Corporate sponsorship of a cause: the role of identification in purchase intent", Journal of Business Research, 58, 268-276.

Cornellssen, J (2000). "Reputation management. Corporate image: an audience centre model". Corporate Communications: An International Journal, 5 (2), 119-125.

Costa, J. (2001). Imagen Corporativa en el siglo XXI, Editorial La Crujía, Buenos Aires.

Cubillo, J.; SÁNChez, J. y Cerviño, J. (2006). "International students' decision-making process", The International Journal of Educational Management, 20 (2), 101-115.

DECLARACIÓN DE BOLONIA (1999).Declaración conjunta de los Ministros Europeos de Educación, Bolonia 19 de junio de 1999.

Delgado, E. (2004). "Estado actual de la investigación sobre la lealtad a la marca: una revisión teórica", Revista de Dirección, Organización y Administración de Empresas, 30, 16-24.

Dutton, J., Dukerich, J. y Harquail, C. (1994). "Organizational Images and Member Identification", Administrative Science Quarterly, 39(2), 239-263.

Engel, J.; Blackwell, R. y Miniard, P. (1990). Consumer Behavior USA. Dryden Press. 6ta Edición.

Elsbach, K. y Bhattacharya, C. (2001). "Defining who you are by what you're not organizational disidentification and the national rifle association". Organization Science, 12(4), 393-413. 
Fishbein, M., y AJzen, I. (1975). Belief, Attitude, Intention, and Behavior: An Introduction to Theory and Research. Reading, MA: Addison-Wesley.

Gallarza, M.; Fayos, T.; Servera, D.; ArteaGA, F. (2008). "Análisis y evaluación del servicio de formación universitaria: implicaciones para el marketing estratégico de las universidades". Ponencia presentada en las VI Jornadas de Redes de Investigación en Docencia Universitaria, Universidad de Alicante, 9 y 10 de junio 2008.

GARCíA DE LOS SALMONES, M. (2001). "La Imagen de Empresa como Factor Determinante en la Elección de Operador: Identidad y Posicionamiento de las Empresas de Comunicaciones Móviles", Tesis Doctoral, Universidad de Cantabria.

GUARDIA, R. (1998). El beneficio de compartir valores. Marketing social corporativo, una nueva estrategia para diferenciar las marcas, Bilbao: Ediciones Deusto, S. A.

Hup, S. (2006). "Organizational identification and commitment of members of a human development organization", Journal of Management Development, 25 (3), 249- 268.

IvY, J. (2001). "Higher education institution image: a correspondence analysis approach", The International Journal of Educational Management, 15(6), 276-82.

Kazoleas, D.; Kim, Y y Moffit, M. (2001). "Institutional image: a case study", Corporate Communications: An International Journal, 6 (24), 205-16.

KreINER, G. y Ashforth, B. (2004). "Evidence toward an expanded model of organizational identification", Journal of Organizational Behaviour, 25, 1-27.

Kotler, P. y ANDREASEN, A. (1996). Strategic Marketing for Nonprofit Organizations, Prentice-Hall, $5^{\text {a }}$ ed., New Jersey.

Hair, J.; ANDERSON, R.; TATHAM, R. y Black, W. (2005). Análisis Multivariante, 5ta. Edición, Prentice Hall, España.

Helgesen, Ø. y Nesset, E. (2007). "Images, Satisfaction and Antecedents: Drivers of Student Loyalty? A case study of a Norwe- gian University College", Corporate Reputation Review, 10(1), 38-59.

Henning-Thurau, T., LANGer, M.; HANSEn, U. (2001). "Modelling and managing student loyalty: an approach based on the concept of relationship quality", Journal of Service Research, Vol. 3 (1), 331-44.

Landrum, R.E., Turrisi, R.; Harless, C. (1998). University image: the benefits of assessment and modelling, Journal of Marketing for Higher Education, 9(1), 53-68.

Luque, T. y DEL BARRIO, S. (2008). "Modeling The University Image: The Faculty's View", ponencia presentada en el 7 International Congress Marketing Trends, Venezia 25-26 enero.

MAel, F. y Ashforth, B. (1992). "Alumni and their alma mater: a partial test of the reformulated model of organizational identification", Journal of Organizational Behavior, 13(2), 103-23.

MARÍN, L. y RuIZ, S. (2007). "La identificación del consumidor con la empresa: más allá del marketing de relaciones", Universia Business Review-Actualidad Económica, 62-75.

Martensen, A., Gronholdt, L., Eskildsen, J. y KRISTENSEN, K. (1999), "Measuring student oriented quality in higher education: application of the ECSI methodology", Conference Proceedings from TQM for Higher Education Institutions. "Higher Education Institutions and the Issue of Total Quality", Verona, 30-31 August.

McInNIS, D. y PRICE, L.(1987). "The Role of Imagery In Information Processing: Review and Extensions", Journal of Consumer Research, Vol. 13, 473-491.

Moles, A. (1983). El Simbolo y la Imagen en la Sociedad Contemporánea, Documentos Internacionales de Comunicación, 1er y $2^{\circ}$ trimestre, Vol. 20/21, 21-34.

Nguyen, N. y LeBlanc, G. (1998). "The mediating role of corporate image on customers' retention decisions: an investigation in financial services2, International Journal of Bank Marketing, 16(2), 52-65. 
Nguyen, N. y Le Blanc, G. (2002). "Contact personnel, physical environment and the perceived corporate image of intangible services by new clients", Internacional Journal of Service Industry Management, 13 (3), 242262.

Nguyen, N; Le Blanc, G. y María, R. (2004). "Elementos que contribuyen a la formación de la imagen en las Cajas Populares: un estudio empírico en Canadá, México y Brasil", VIII Seminario Internacional Nuevas propuestas de gestión, 4 al 8 de octubre, Canadá

Norusis, M. J. (1993): SPSS. Statistical Data Analysis. SPSS Inc.

Paramewaran, R.; Glowacka, A.E. (1995): University image: an information processing perspective, Journal of Marketing for Higher Education, 6(2), 41-56.

Reynolds, T. y Gutman, J. (1984). "Advertising is Image Management", Journal of Tinto, V. (1975). "Dropout from Higher Education: A theoretical synthesis of recent rese- arch", Review of Educational Research 45, 89-125.

Scott, S. y Lane, V. (2000). "A stakeholder approach to organizational identity", The Academy of Management Review, January 25: 1, 49-62.

SöDERLUND, M. (2006). "Measuring customer loyalty with multi-item scales: A case for caution", International Journal of Service Industry Management, 17(1), 76-98.

Traverso, J.; Cortes, M. y Roman, O. (2007). "Análisis de la Imagen Interna de Institución Universitaria. Construcción de un Modelo para la Obtención de la Imagen Bajo la Perspectiva del Alumno". Investigaciones Europeas de Dirección y Economía de la Empresa. 13 (1), 231-246.

Williams, S. y Moffitt, M. (1997). "Corporate image as an impression formation process: prioritizing personal, organizational, and environmental audience factors", Journal of Publics Relations Research, 9 (4), 237-58.
Fecha recepción: 10/12/2009

Fecha aceptación: 08/11/2011 
